\title{
Coming of age, becoming obese: a cross- sectional analysis of obesity among adolescents and young adults in Malaysia
}

Christopher Pell ${ }^{1 *}$, Pascale Allotey ${ }^{2,3}$, Natalie Evans ${ }^{4}$, Anita Hardon ${ }^{1}$, Johanna D. Imelda ${ }^{5}$, Ireneous Soyiri' ${ }^{2,6}$, Daniel D. Reidpath ${ }^{2,3}$ and The SEACO Team

\begin{abstract}
Background: Malaysians have become increasingly obese over recent years. The transition from adolescence to early adulthood is recognized as critical for the development of eating and activity habits. However, little obesityrelated research focuses on this life stage. Drawing on data from a health and demographic surveillance site in Malaysia, this article describes obesity and overweight amongst adolescents and young adults in a multi-ethnic population.

Methods: Data were collected at the South East Asia Community Observatory (SEACO) in Segamat District, Johor. In this dynamic cohort of approximately 40,000 people, 5,475 were aged 16-35 in 2013-2014. The population consists of Malay, Chinese, Indian and Indigenous (Orang Asli) families in proportions that reflect the national ethnic diversity. Data were collected through health profiles (Body Mass Index [BMI] measurements in homes) and selfreport questionnaires.

Results: Age and ethnicity were associated with overweight (BMI $25.0-29.9 \mathrm{Kg} / \mathrm{m}^{2}$ ) and obesity (BMI $\geq 30 \mathrm{Kg} / \mathrm{m}^{2}$ ). The prevalence of overweight was $12.8 \%$ at ages $16-20$ and $28.4 \%$ at ages $31-35$; obesity was $7.9 \%$ and $20.9 \%$ at the same age groups. The main ethnic groups also showed varied patterns of obesity and overweight at the different age groups with Chinese at lowest and Orang Asli at highest risk. Level of education, employment status, physical activity and frequency of eating out were poorly predictive of overweight and obesity.

Conclusion: The pattern of overweight and obesity in the 16-35 age group further highlights this as a significant period for changes in health-related behaviours. Further longitudinal research is however needed to confirm the observed pattern and investigate causal factors.
\end{abstract}

Keywords: Obesity, Malaysia, Overweight, Adolescents, Physical activity

\section{Background}

With increasing rates and links to significant morbidity and mortality from non-communicable diseases (NCDs), such as type two diabetes, cardiovascular disease and various cancers, obesity is now a urgent global health issue [1]. Indeed, obesity is a public health priority in low and middle income countries, where, in some instances, rates surpass those of wealthier nations [2] and where health systems face the complex public health

\footnotetext{
* Correspondence: c.l.pell@uva.nl

${ }^{1}$ Centre for Social Science and Global Health, University of Amsterdam,

Nieuwe Achtergracht 166, 1018 W Amsterdam, The Netherlands

Full list of author information is available at the end of the article
}

challenges of both over and under-nutrition [3]. Moreover, in Asian populations, because standard Body Mass Index (BMI) thresholds for overweight/obesity (25 and $30 \mathrm{Kg} / \mathrm{m} 2$ respectively) have been linked with higher levels of body fat than other populations $[4,5]$ obesityrelated disease burdens may be underestimated [6].

Obesity rates vary notably across South East Asia, with Malaysia and Singapore recording some of the highest levels [2]. In Malaysia, obesity rates have increased over the last 20 years [7] and this is now a critical public health issue and a priority research area [8]. In these multi-ethnic states, obesity/overweight rates vary across population groups, with the Malay and Indian ethnic 
groups generally recording a higher prevalence than the ethnic Chinese [7, 9-11]. Age, gender, wealth and education have also been identified as factors that influence obesity prevalence $[12,13]$. The reasons for the ethnic variations however remain unclear, particularly given their similar exposure to obesogenic environments [14].

Obesity often results from the cumulative effects of years of eating patterns and physical inactivity established at a younger age. In this regard, the transition from adolescence to early adulthood is a critical period [15], with longitudinal research showing that obesity prevalence increases notably during this time [16]. During these formative years, peer influences, transition from school to higher education or employment, new found independence and exposure to new foods, behaviors and environments create a complex ecological system that adolescents navigate and that influences future behaviours.

Population-based studies on obesity and other NCD risks are beginning to build an evidence base. However, there are a number of key areas for which there remains a dearth of data. For example, to date, little research in Asia has investigated the transition from adolescence to early adulthood with regard to its relevance for the development of obesity/overweight. Drawing on data from a multi-ethnic population in rural and semi-urban Malaysia - the South East Asia Community Observatory (SEACO) - this article explores obesity and overweight amongst adolescents and young adults. The following questions are therefore addressed: what are the rates of overweight and obesity among adolescents and young adults? How do the rates vary across the different ethnic groups? How do eating habits (particularly eating outside of the home) vary across the different age groups? How does physical activity vary across the different ethnicities and age groups? What are the factors associated with BMI across these age groups? The responses to these questions will underpin any future longitudinal research on adolescents' transition to adulthood and its influence on obesity-related behaviours.

\section{Methods}

\section{Setting}

SEACO is a health and demographic surveillance site (HDSS) located in Segamat District, Johor, Malaysia. Established in late 2011, SEACO covers a population of approximately 40000 from about 11000 households in rural, semi-urban and plantation areas. The ethnic mix of the population reflects the national proportions of Malay (60\%), Chinese (23\%) and Indian (7\%) descent, as well as gender (49\% male and $51 \%$ female). This population is spread over five of the 11 sub-districts that comprise Segamat District

Data from the 2012 SEACO census suggest that around half of 15- to 20-year-olds migrate out of the district. In absolute terms, this is highest amongst the Malay ethnic group, however, in relative terms, the Chinese male population exhibits the highest proportion of group outmigration, with the population decreasing by more than two thirds [17]. This outmigration is linked to the transitions that they undertake between adolescence and early adulthood. Around $70 \%$ of Malaysians attend secondary education [18], and they are required to remain an additional 18 months to gain qualifications for higher education (form six). One fifth of young people subsequently enroll in higher education [19]. Nationally, youth unemployment rates are around $10 \%[20]$.

\section{Population, sample and data collection}

During the initial 2012 SEACO census, all households within the five selected subdistricts in Segamat were visited to enumerate and enroll the population into the longitudinal dynamic cohort $[17,21]$. A response rate of approximately $85 \%$ was achieved across the total population. This was followed by a health baseline survey in 2013. In this article, only data on young people are reported: 16-35- year-olds, which is a range used in a number of low and middle income countries, to take account of the levels of autonomy and opportunities available within the specific development contexts [22]. The total population in this age group was 5,475.

Data were collected by a team of community-based data collectors able to communicate in relevant languages (Bahasa Malay, Chinese, English and Tamil). Data were recorded directly on Android mobile devices with survey forms designed in Open Data Kit (ODK). Data on the tablets are encrypted and are then uploaded to a secure server and encrypted again.

\section{Assessment tools}

The health round survey comprised several modules that covered socio-demographic data, health service utilization, height and weight measurements, physical activity and self-reported health status, health service utilisation and quality of life measures. Socio-demographic data collected included: age; sex; ethnicity (Malay, Chinese, Indian, Orang Asli or Other); education (primary; secondary; tertiary) and employment.

Physical activity was measured using the WHO Global Physical Activity Questionnaire (GPAQ). The 16-item instrument, validated for the Malaysian context [23], estimates physical activity in the domains of work, transport and leisure as well as sedentary behavior [24]. The guidelines prescribed by the WHO GPAQ tool were followed to derive supplementary variables (total physical activity and the binary categories of active ( $>600$ Metabolic Equivalent of Tasks [METs] per week) and inactive (<600 METS per week)) [25]. 
Participants' height (meters) and weight (kilograms) were measured using a TRANSTEK scale with height gauge (GBS-721). BMI was calculated from these measures. The average number of meals eaten outside the home (per week) was self-reported. No details were collected on specific dietary intake or composition.

\section{Analysis \\ Body Mass Index (BMI)}

For 20- to 35-year-olds, Body Mass Index (BMI) was classified using standard WHO categories: underweight $<18.5 \mathrm{~kg} / \mathrm{m}^{2}$; normal $18.5-24.9 \mathrm{~kg} / \mathrm{m}^{2}$; overweight $25.0-$ $29.9 \mathrm{~kg} / \mathrm{m}^{2}$; obese $\geq 30.0 \mathrm{~kg} / \mathrm{m}^{2}$. For 16 - to 19 -year-olds, the WHO gender-specific zBMI scores were used to calculate the thresholds. Calculating these cut-offs entailed taking the means of males and females values over the monthly intervals that are specified by the WHO. Therefore, for the 16- to 20-year-old age group, between the ages of 16 years 0 months and 19 years 0 months, the zBMI scores (whereby underweight $<-1$ standard deviation (SD); normal -1SD to +1SD; overweight: +1SD to +2SD; obesity: > + 2SD) were averaged along with the standard adult BMI cut-offs between 19 years 1 month and 20 years 11 months. For this group, with both sexes combined the cut-offs were: underweight $<18.7 \mathrm{~kg} / \mathrm{m}^{2}$; normal $18.7-24.7 \mathrm{~kg} / \mathrm{m}^{2} 7 \mathrm{kgm}^{2}$; overweight $24.7-29.3 \mathrm{~kg} / \mathrm{m}^{2}$; and obese $\geq 29.3 \mathrm{~kg} / \mathrm{m}^{2}$. Data on prevalence of underweight, normal weight, overweight and obese amongst 16- to 35year-olds are presented.

\section{Physical activity}

The internal consistency of the list of 16 GPAQ questions were assessed using Cronbach's alpha [26]. All the questions had high coefficients of reliability ranging from 79 to $91 \%$. Hence the internal consistency of the GPAQ test scale exceeds the minimum threshold (of alpha values of 0.7 to 0.8 ) recommended for comparing groups [27].

\section{Associations}

Multinomial logistic regression models were fitted to the categories of BMI using the social and demographic factors collected as part of the health round. The models presented are based on data from those who responded to the survey questions relevant to obesity risk, a total of 5,319 Malaysian youth.

\section{Results}

The 16- to 35-year-old population for whom data were collected in the SEACO health round is majority Malay (72.6 \% and slightly higher than the SEACO population as a whole), followed by Chinese (14.9 \%), Indian $(10.1 \%)$ and Orang Asli (2.4\%). A majority received some secondary education (76.2 \%) and most (64.8\%) remain unmarried. One quarter were students and just over one third were in full-time employment $(34.1 \%)$ (see Table 1).

Sixty percent of this group were classified as active (>600 METS) and just over half classified as normal for BMI. Using standard WHO thresholds, the prevalence of overweight was significantly higher among males than in females (i.e., $21.0 \%$ compared to $18.7 \%$ ), but obesity was significantly higher in females (15.4\% compared to $11.1 \%)$. These differences were statistically significant $(p<0.001)$ (see Table 2).

BMI categories were charted across the age groups (Table 2, Figs. 1 and 2). Obesity and overweight at ages 31-35 are higher than at ages $16-20$ (8.4\% compared to $20.9 \%$, and $12.8 \%$ compared to $28.4 \%$ respectively). The proportion of underweight and normal BMI is also lower in the older age groups (21.7\% at ages $16-20$ versus $4.6 \%$ at ages $31-35,56.7 \%$ at ages $16-20$ and $46.1 \%$ at age $31-35$ respectively). Figure 2 also indicates the differences in age-specific prevalence of obesity, overweight, normal and underweight by gender.

The Orang Asli record the highest prevalence of obesity amongst the ethnic groups $(22.8 \%)$. Obesity is lowest amongst the Chinese (7.6\%). The greatest difference in obesity rates across the age groups occurs in the Indian population $(6.0 \%$ among the 16 - to 20 -year-olds to $28.1 \%$ among 31- to 35-year-olds). The Chinese demonstrate the lowest difference in obesity prevalence.

The relationship of obesity to physical activity and eating out are less clear. The Orang Asli reported the lowest frequencies of eating out (around once a week). The Indian youth ate out approximately six to nine times each week (Table 2). The lowest level of physical activity was recorded in the 31- to 35-year-old Orang Asli and Indians.

A multinomial logistic regression was conducted with social, demographic and behavioural factors (eating out and physical activity) using normal BMI as the base outcome for comparisons (see Table 3). The results indicate that one unit increase in age leads to an increased probability of $1.05(P<0.001)$ of being overweight and 1.06 $(P<0.001)$ increase of being obese. The relative risk ratios (RRRs) compare Indian, Chinese, and Orang Asli to Malay with normal BMI as the base outcome. The Orang Asli youth have double the relative risk of being overweight $(P=0.002)$ if all other variables are held constant. Being Chinese reduces the risk of overweight (by a factor of $0.74, P<0.05$ ) and the risk of obesity (by a factor of $0.46, P<0.001)$. Indian ethnicity increases the risk of underweight $(P=0.002)$. Other factors that affect the likelihood of being overweight are marriage and employment status.

Age, ethnicity, marital status and employment status are therefore statistically significant predictors of BMI 
Table 1 Population characteristics

\begin{tabular}{|c|c|c|c|c|c|c|}
\hline & \multicolumn{2}{|l|}{ Male } & \multicolumn{2}{|c|}{ Female } & \multicolumn{2}{|c|}{ Male \& female } \\
\hline & $n$ & $\%$ & $n$ & $\%$ & $n$ & $\%$ \\
\hline \multicolumn{7}{|l|}{ Age (years) } \\
\hline $16-20$ & 935 & 37.4 & 1021 & 36.2 & 1956 & 36.8 \\
\hline $21-25$ & 540 & 21.6 & 610 & 21.7 & 1150 & 21.6 \\
\hline $26-30$ & 518 & 20.7 & 580 & 20.6 & 1098 & 20.6 \\
\hline $31-35$ & 509 & 20.3 & 606 & 21.5 & 1115 & 21.0 \\
\hline Total & 2502 & 47.0 & 2817 & 53.0 & 5319 & 100.0 \\
\hline \multicolumn{7}{|l|}{ Ethnicity } \\
\hline Malay & 1869 & 74.7 & 1985 & 70.6 & 3854 & 72.6 \\
\hline Chinese & 373 & 14.9 & 419 & 14.9 & 792 & 14.9 \\
\hline Indian & 215 & 8.6 & 323 & 11.5 & 538 & 10.1 \\
\hline Orang Asli & 43 & 1.7 & 84 & 3.0 & 127 & 2.4 \\
\hline \multicolumn{7}{|l|}{ Education } \\
\hline None & 6 & 0.2 & 11 & 0.4 & 17 & 0.3 \\
\hline Primary & 113 & 4.5 & 145 & 5.2 & 258 & 4.9 \\
\hline Secondary & 1949 & 78.4 & 2077 & 74.2 & 4026 & 76.2 \\
\hline Tertiary & 257 & 10.3 & 407 & 14.5 & 664 & 12.6 \\
\hline Other & 160 & 6.4 & 158 & 5.6 & 318 & 6.0 \\
\hline \multicolumn{7}{|l|}{ Marital Status } \\
\hline Never married & 1759 & 73.8 & 1542 & 56.9 & 3301 & 64.8 \\
\hline Married & 615 & 25.8 & 1113 & 41.0 & 1728 & 33.9 \\
\hline Separated & 1 & 0.0 & 12 & 0.4 & 13 & 0.3 \\
\hline Divorced & 8 & 0.3 & 37 & 1.4 & 45 & 0.9 \\
\hline Widow(er) & 0 & 0.0 & 7 & 0.3 & 7 & 0.1 \\
\hline Cohabiting & 0 & 0.0 & 1 & 0.0 & 1 & 0.0 \\
\hline \multicolumn{7}{|l|}{ Employment } \\
\hline Too young & 53 & 2.1 & 74 & 2.6 & 127 & 2.4 \\
\hline Student & 615 & 24.7 & 719 & 25.7 & 1334 & 25.2 \\
\hline House-wife/-husband & 5 & 0.2 & 668 & 23.9 & 673 & 12.7 \\
\hline Not working & 239 & 9.6 & 323 & 11.5 & 562 & 10.6 \\
\hline Casual employment & 27 & 1.1 & 13 & 0.5 & 40 & 0.8 \\
\hline Part-time & 116 & 4.7 & 146 & 5.2 & 262 & 5.0 \\
\hline Full-time & 1056 & 42.3 & 747 & 26.7 & 1803 & 34.1 \\
\hline Self employed & 383 & 15.4 & 108 & 3.9 & 491 & 9.3 \\
\hline \multicolumn{7}{|l|}{ Physical activity } \\
\hline Active & 366 & 66.2 & 255 & 53.3 & 621 & 60.2 \\
\hline Inactive & 187 & 33.8 & 223 & 46.7 & 410 & 39.8 \\
\hline \multicolumn{7}{|l|}{ Body mass index } \\
\hline Underweight (BMI <18.5) & 311 & 12.9 & 382 & 13.9 & 693 & 13.4 \\
\hline Normal (BMI 18.5-24.9) & 1329 & 55.1 & 1422 & 51.9 & 2751 & 53.4 \\
\hline Overweight (BMI 25.0-29.9) & 506 & 21.0 & 513 & 18.7 & 1019 & 19.8 \\
\hline Obese (BMI $\geq 30.0$ ) & 267 & 11.1 & 423 & 15.4 & 690 & 13.4 \\
\hline
\end{tabular}


Table 2 Prevalence of obesity, overweight, normal, underweight, inactive and the mean number of meals eaten outside the home according to age group and ethnicity

\begin{tabular}{|c|c|c|c|c|c|c|}
\hline & \multirow[t]{2}{*}{ Age group / years } & \multicolumn{5}{|l|}{ Ethnicity } \\
\hline & & Malay & Chinese & Indian & Orang Asli & All \\
\hline \multirow{4}{*}{$\begin{array}{l}\text { Obesity } \\
\left(\mathrm{BMI} \geq 30 \mathrm{~kg} / \mathrm{m}^{2 \mathrm{a}}\right) \text { prevalence / \% }\end{array}$} & $16-20$ & 9.5 & 5.3 & 6.0 & 17.6 & 8.4 \\
\hline & $21-25$ & 11.4 & 6.6 & 15.9 & 20.0 & 11.5 \\
\hline & $26-30$ & 17.4 & 11.8 & 15.2 & 21.9 & 16.7 \\
\hline & $31-35$ & 20.6 & 12.3 & 28.1 & 34.4 & 20.9 \\
\hline \multirow{4}{*}{$\begin{array}{l}\text { Overweight } \\
\text { (BMl } 25.0-29.9 \mathrm{~kg} / \mathrm{m}^{2 \mathrm{~b}} \text { ) prevalence / \% }\end{array}$} & $16-20$ & 12.0 & 14.4 & 14.3 & 14.7 & 12.8 \\
\hline & $21-25$ & 18.7 & 20.7 & 17.8 & 32.0 & 19.1 \\
\hline & $26-30$ & 26.2 & 13.6 & 26.3 & 53.1 & 25.7 \\
\hline & $31-35$ & 28.8 & 25.4 & 26.6 & 37.5 & 28.4 \\
\hline \multirow{4}{*}{$\begin{array}{l}\text { Normal } \\
\text { (BMl } 18.5-24.9 \mathrm{~kg} / \mathrm{m}^{2 \mathrm{c}} \text { ) prevalence / \% }\end{array}$} & $16-20$ & 56.8 & 59.8 & 50.0 & 52.9 & 56.7 \\
\hline & $21-25$ & 56.6 & 57.9 & 43.9 & 48.0 & 55.3 \\
\hline & $26-30$ & 47.5 & 65.5 & 48.5 & 25.0 & 48.8 \\
\hline & $31-35$ & 45.2 & 60.1 & 41.7 & 28.1 & 46.1 \\
\hline \multirow{4}{*}{$\begin{array}{l}\text { Underweight } \\
\left(\mathrm{BMl}<18.5 \mathrm{~kg} / \mathrm{m}^{2 \mathrm{~d}}\right) \text { prevalence } / \%\end{array}$} & $16-20$ & 21.7 & 20.6 & 29.7 & 14.7 & 22.1 \\
\hline & $21-25$ & 13.4 & 14.9 & 22.4 & 0.0 & 14.1 \\
\hline & $26-30$ & 8.9 & 9.1 & 10.1 & 0.0 & 8.7 \\
\hline & $31-35$ & 5.4 & 2.2 & 3.6 & 0.0 & 4.6 \\
\hline \multirow{4}{*}{$\begin{array}{l}\text { Prevalence inactive } \\
(<600 \text { METs per week) / \% }\end{array}$} & $16-20$ & 47.8 & 47.1 & 44.1 & 32.0 & 46.5 \\
\hline & $21-25$ & 39.7 & 20.7 & 28.6 & 33.3 & 35.2 \\
\hline & $26-30$ & 35.9 & 27.6 & 25.0 & 18.8 & 30.8 \\
\hline & $31-35$ & 36.9 & 46.9 & 12.5 & 15.8 & 34.4 \\
\hline \multirow{4}{*}{$\begin{array}{l}\text { Mean number of meals eaten outside the home } \\
\text { (95\% Cl) }\end{array}$} & $16-20$ & $4.6(4.3-4.9)$ & $4.0(3.1-4.9)$ & $6.5(5.9-7.2)$ & $1.1(0.6-1.5)$ & $4.9(4.6-5.2)$ \\
\hline & $21-25$ & $5.4(5.0-5.8)$ & $4.2(3.0-5.3)$ & $9.0(7.9-10.3)$ & $0.8(0.3-1.3)$ & $5.7(5.3-6.0)$ \\
\hline & $26-30$ & $5.2(4.8-5.5)$ & $4.8(3.4-6.1)$ & $6.8(5.6-8.0)$ & $1.0(0.0-2.0)$ & $5.1(4.8-5.4)$ \\
\hline & $31-35$ & $4.5(4.1-4.8)$ & $2.7(1.9-3.5)$ & $6.3(5.2-7.4)$ & $0.8(0.2-1.5)$ & $4.4(4.1-4.7)$ \\
\hline
\end{tabular}

among the population of Segamat 16- to 35-year-olds. Being physically inactive did not however produce a significant RRR value for any of the BMI categories relative to normal; nor did level of education.

\section{Discussion}

The levels of obesity and overweight across the 16- to 35-year-old age group of SEACO participants further highlight the significance of this life stage in terms of trends in BMI. Relatively little obesity-related research in Malaysia has focused on young people and few data are directly comparable with those presented above. Furthermore, because of differences in study design comparisons with the available studies of young Malaysian's obesity rates, diets and activity habits (e.g., $[28,29])$ are of little value. Nonetheless, the SEACO data are in line with the increases in obesity prevalence reported in a variety of studies across Malaysia since the mid-1990s [7]. The pattern amongst the Orang Asli is particularly pronounced but this may be a result of the small number of respondents: a total of 123 respondents provided information on height and weight for the health round.

The increasing obesity prevalence in Malaysia has been explained in terms of the concurrent rise in national wealth, urbanization and industrialization [30]. Although often termed a "disease of affluence", crossnational comparisons indicate that the association between national wealth and obesity prevalence is more nuanced [3]. This emphasizes the need to investigate Malaysia's obesity epidemic in its own terms, exploring both rural and urban environments to identify the obesogenic factors [31]. Several of these obesogenic factors are in evidence in Segamat as in many other areas of Malaysia. For example, Western fast food outlets are a growing enterprise [30], with, amongst others, McDonalds, KFC and Pizza Hut popular eateries whose advertising is often aimed at young people. 


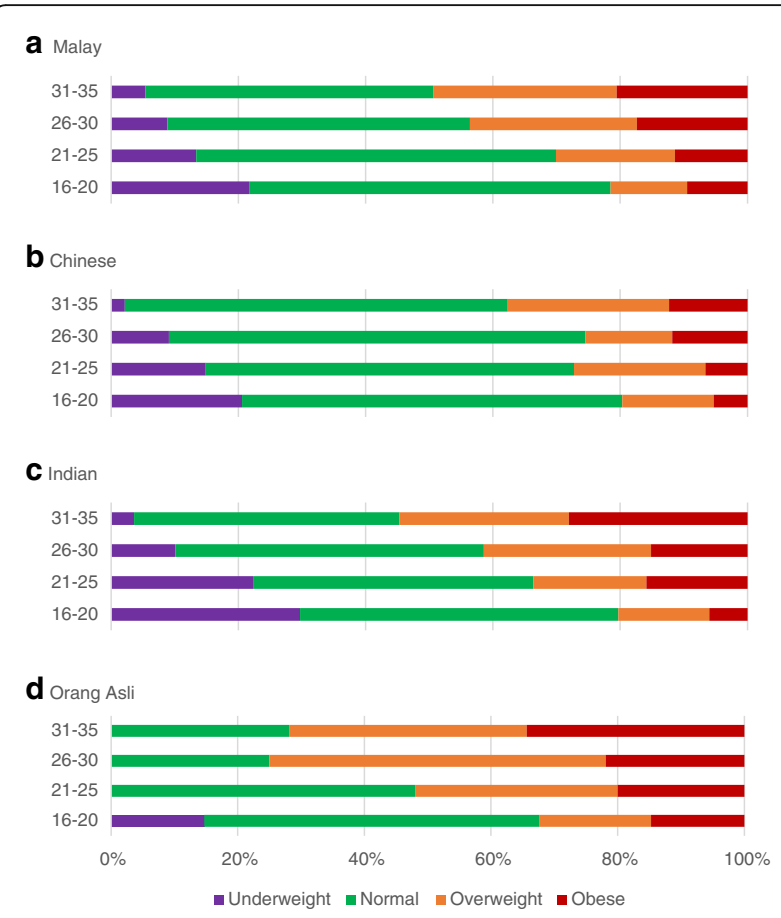

Fig. 1 Prevalence of BMl categories amongst the different age groups by major ethnic group

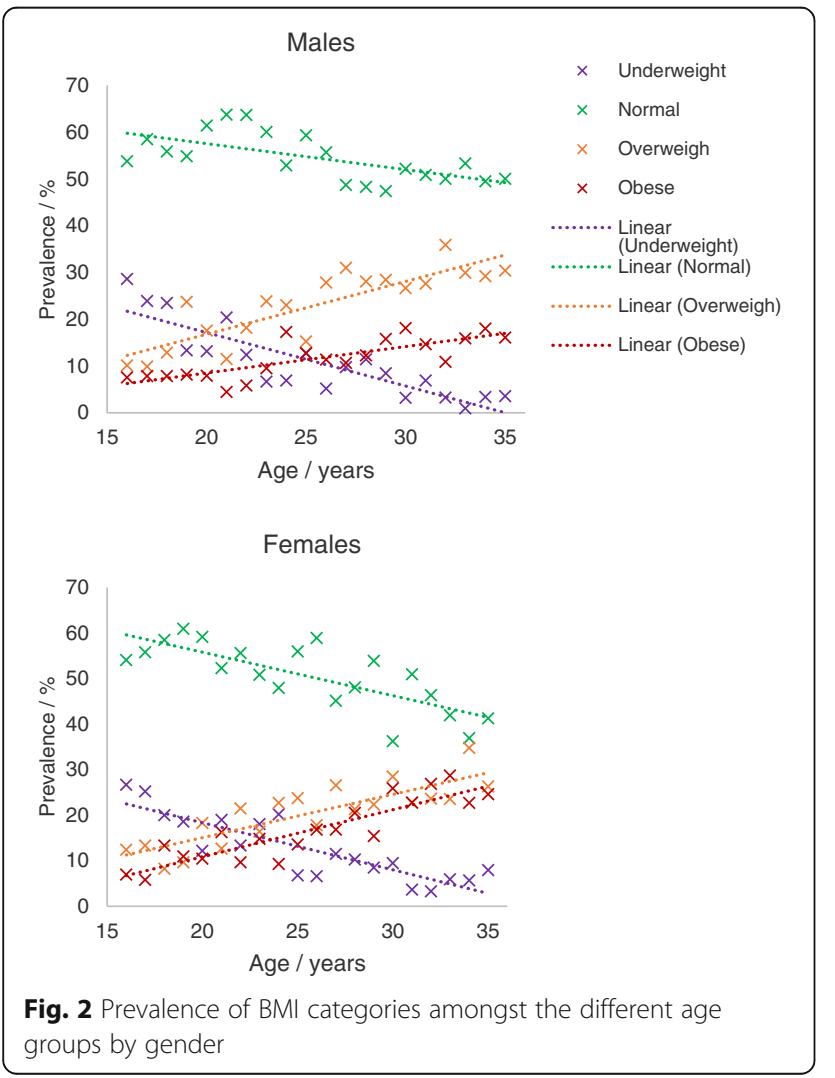

Furthermore, if considered expensive, cheaper local imitations (for example, Ramly burgers) are widely available. The ubiquity of fried food - whether, local, Western or a mix - is also reflected in patterns of cooking oil consumption: global trends, whereby increased vegetable oil consumption contributed to rises in calorie consumption between the mid-1980s and 2000s [32], are particularly apparent in Malaysia, where per capita consumption of fats and oils - particularly palm oil is among the highest in Asia, [33]. Indeed, the economic importance of palm oil to Malaysia is keenly visible in Segamat, where palm plantations dominate the landscape.

Levels of physical activity are comparable with data from other studies using the GPAQ in Malaysia [34]. Again, research in this area is limited, with the last population-based survey from 2002 to 2003 indicating low levels (14\% of respondents) of physical activity [35]. This inactivity is partly attributed to the primacy of motor vehicles and motorcycles for transport. Indeed, other data from the SEACO surveys emphasize the ubiquity of car ownership, with at least one vehicle in every household. Observations in Segamat also lay bare the lack of pedestrian and cyclist-friendly infrastructure. Few journeys are therefore taken on foot or by bicycle.

In terms of eating out, a recent review identified associations between eating out and higher total energy and fat intake [36]. The SEACO data however suggest little connection between overweight or obesity, and eating out. In this context, (as it may be in others), the relationship between eating out and overweight/obesity is therefore probably more complex. This resonates with studies that have drawn attention to the significance of the type of restaurant/fast food outlet, rather than just eating out [37]. Research elsewhere in South East Asia has also highlighted that eating out does not necessarily entail higher intake of fat and energy [38].

\section{Strengths, limitations and further research}

Broader inferences of prevalence from this study are limited by the focus on a single predominantly rural community (albeit with some semi-rural areas); SEACO was set up to explore the nature of relationships and seek detailed explanations for changes to population health and wellbeing, and not necessarily to produce nationally representative epidemiological data. Nonetheless, cross-sectional data generated from the platform provide a detailed picture of the whole community as opposed to samples of populations. In addition, relatively little obesity-related research has been undertaken in Malaysia, or indeed in the region, that focuses on adolescence and early adulthood. Small studies have been undertaken in targeted small 
Table 3 Predictors of BMI among overweight and obese 16-35 year olds (with normal BMI as the reference group)

\begin{tabular}{|c|c|c|c|c|c|c|c|c|c|}
\hline \multirow{3}{*}{$\begin{array}{l}\text { Characteristic } \\
\text { Over weight }\end{array}$} & \multicolumn{3}{|c|}{$\underline{\text { Unadjusted models }}$} & \multicolumn{3}{|c|}{ Base model: with all predictors } & \multicolumn{3}{|c|}{ Reduced model: with selected predictors } \\
\hline & \multirow{4}{*}{$\begin{array}{l}\text { RRR } \\
1.07^{* * *}\end{array}$} & \multicolumn{2}{|c|}{$[95 \% \mathrm{Cl}]$} & \multirow{2}{*}{$\begin{array}{l}\text { RRR } \\
1.03^{* * *}\end{array}$} & \multicolumn{2}{|c|}{$[95 \% \mathrm{Cl}]$} & \multirow{2}{*}{$\begin{array}{l}\text { RRR } \\
1.05^{* * *}\end{array}$} & \multicolumn{2}{|c|}{$[95 \% \mathrm{Cl}]$} \\
\hline & & & & & & & & & \\
\hline Age (years) & & 1.0566 & 1.0818 & & 1.0111 & 1.0492 & & 1.0328 & 1.0650 \\
\hline \multicolumn{9}{|l|}{ Sex } & \\
\hline Male & 1.00 & & & 1.00 & & & & & \\
\hline Female & 0.99 & 0.8566 & 1.1369 & 0.90 & 0.7585 & 1.0661 & & & \\
\hline \multicolumn{10}{|l|}{ Ethnicity } \\
\hline Malay & 1.00 & & & 1.00 & & & 1.00 & & \\
\hline Indian & 1.16 & 0.9079 & 1.4724 & 1.11 & 0.8602 & 1.4413 & 1.07 & 0.8300 & 1.3821 \\
\hline Chinese & $0.74^{* * *}$ & 0.5966 & 0.9068 & 0.86 & 0.6876 & 1.0719 & 0.82 & 0.6563 & 1.0141 \\
\hline Other & $0.53^{*}$ & 0.2983 & 0.9539 & $0.37^{* * *}$ & 0.1884 & 0.7297 & $0.45^{* *}$ & 0.2516 & 0.8158 \\
\hline Orang asli & $2.32^{* * *}$ & 1.5143 & 3.5395 & $1.70^{*}$ & 1.0516 & 2.7548 & $1.86^{* *}$ & 1.1983 & 2.9008 \\
\hline \multicolumn{10}{|l|}{ Marital status } \\
\hline Married & 1.00 & & & 1.00 & & & 1.00 & & \\
\hline Not married & $0.45^{* * *}$ & 0.3883 & 0.5214 & $0.67^{* * *}$ & 0.5408 & 0.8277 & $0.68^{* * *}$ & 0.5584 & 0.8160 \\
\hline Eating out & $0.98^{* * *}$ & 0.9706 & 0.9939 & $0.98^{* *}$ & 0.9703 & 0.9959 & 0.99 & 0.9771 & 1.0016 \\
\hline \multicolumn{10}{|l|}{ Education } \\
\hline None & 1.00 & & & 1.00 & & & & & \\
\hline Other & 1.78 & 0.3877 & 8.1702 & 3.33 & 0.6942 & 15.9796 & & & \\
\hline Primary & 3.66 & 0.8043 & 16.6475 & 3.19 & 0.6815 & 14.9765 & & & \\
\hline Secondary & 2.43 & 0.5475 & 10.8000 & 2.72 & 0.5919 & 12.5298 & & & \\
\hline Tertiary & 2.61 & 0.5810 & 11.7014 & 3.32 & 0.7129 & 15.5032 & & & \\
\hline \multicolumn{10}{|l|}{ Employment } \\
\hline Full-time & 1.00 & & & 1.00 & & & & & \\
\hline Student & $0.45^{* * *}$ & 0.3630 & 0.5491 & $0.66^{* * *}$ & 0.5004 & 0.8783 & & & \\
\hline House-wife/-husband & 1.18 & 0.9483 & 1.4623 & 0.93 & 0.7132 & 1.2116 & & & \\
\hline Not working & $0.54^{* * *}$ & 0.4051 & 0.7112 & $0.69^{*}$ & 0.5053 & 0.9412 & & & \\
\hline Casual jobs & 1.32 & 0.6372 & 2.7140 & 1.15 & 0.5360 & 2.4560 & & & \\
\hline Part-time & 1.02 & 0.7276 & 1.4344 & 1.14 & 0.8073 & 1.6180 & & & \\
\hline Pensioner & 0.00 & 0.0000 & & 0.00 & 0.0000 & . & & & \\
\hline Self employed & 1.24 & 0.9779 & 1.5744 & 1.24 & 0.9609 & 1.5998 & & & \\
\hline Too young & $0.41^{* * *}$ & 0.2195 & 0.7691 & 0.66 & 0.3321 & 1.2981 & & & \\
\hline Total physical activity & 1.00 & 0.9992 & 1.0013 & 1.00 & 0.9988 & 1.0012 & & & \\
\hline \multicolumn{10}{|l|}{ Obese } \\
\hline Age (years) & $1.08^{* * *}$ & 1.0640 & 1.0939 & $1.06^{* * *}$ & 1.0348 & 1.0794 & $1.06^{* * *}$ & 1.0406 & 1.0785 \\
\hline \multicolumn{10}{|l|}{ Sex } \\
\hline Male & 1.00 & & & 1.00 & & & & & \\
\hline Female & $1.52^{* * *}$ & 1.2847 & 1.8020 & $1.23^{*}$ & 1.0023 & 1.5055 & & & \\
\hline \multicolumn{10}{|l|}{ Ethnicity } \\
\hline Malay & 1.00 & & & 1.00 & & & 1.00 & & \\
\hline Indian & 1.26 & 0.9627 & 1.6460 & 1.18 & 0.8917 & 1.5691 & 1.21 & 0.9123 & 1.5930 \\
\hline Chinese & $0.46^{* * *}$ & 0.3485 & 0.6188 & $0.55^{* * *}$ & 0.4054 & 0.7349 & $0.56^{* * *}$ & 0.4173 & 0.7499 \\
\hline Other & $0.16^{* * *}$ & 0.0514 & 0.5230 & $0.11^{* * *}$ & 0.0350 & 0.3757 & $0.14^{* * *}$ & 0.0442 & 0.4547 \\
\hline
\end{tabular}


Table 3 Predictors of BMI among overweight and obese 16-35 year olds (with normal BMI as the reference group) (Continued)

\begin{tabular}{|c|c|c|c|c|c|c|c|c|c|}
\hline Orang asli & $2.29^{* * *}$ & 1.4289 & 3.6774 & 1.34 & 0.7833 & 2.2757 & $1.81^{*}$ & 1.1112 & 2.9555 \\
\hline \multicolumn{10}{|l|}{ Marital status } \\
\hline Married & 1.00 & & & 1.00 & & & 1.00 & & \\
\hline Not married & $0.43^{* * *}$ & 0.3661 & 0.5155 & 0.85 & 0.6587 & 1.0936 & $0.73^{* * *}$ & 0.5830 & 0.9045 \\
\hline Eating out & $0.96^{* * *}$ & 0.9451 & 0.9746 & $0.98^{* * *}$ & 0.9595 & 0.9912 & $0.97^{* * *}$ & 0.9538 & 0.9846 \\
\hline \multicolumn{10}{|l|}{ Education } \\
\hline None & 1.00 & & & 1.00 & & & & & \\
\hline Other & 0.46 & 0.1542 & 1.3978 & 1.07 & 0.3285 & 3.5024 & & & \\
\hline Primary & 1.21 & 0.4146 & 3.5511 & 1.32 & 0.4249 & 4.1195 & & & \\
\hline Secondary & 0.66 & 0.2355 & 1.8690 & 0.89 & 0.2930 & 2.6764 & & & \\
\hline Tertiary & 0.53 & 0.1828 & 1.5295 & 0.84 & 0.2682 & 2.6047 & & & \\
\hline \multicolumn{10}{|l|}{ Employment } \\
\hline Full-time & 1.00 & & & 1.00 & & & & & \\
\hline Student & $0.47^{* * *}$ & 0.3641 & 0.6126 & 0.83 & 0.5893 & 1.1827 & & & \\
\hline House-wife/-husband & $2.08^{* * *}$ & 1.6485 & 2.6299 & $1.43^{*}$ & 1.0666 & 1.9125 & & & \\
\hline Not working & 1.11 & 0.8342 & 1.4676 & 1.33 & 0.9659 & 1.8338 & & & \\
\hline Casual jobs & 0.79 & 0.2687 & 2.3427 & 0.78 & 0.2592 & 2.3545 & & & \\
\hline Part-time & 1.08 & 0.7102 & 1.6296 & 1.13 & 0.7373 & 1.7291 & & & \\
\hline Pensioner & 0.00 & 0.0000 & & 0.00 & 0.0000 & & & & \\
\hline Self employed & 1.15 & 0.8492 & 1.5505 & 1.12 & 0.8113 & 1.5347 & & & \\
\hline Too young & 0.81 & 0.4366 & 1.4870 & 1.38 & 0.7004 & 2.7194 & & & \\
\hline Total physical activity & 1.00 & 0.9990 & 1.0015 & 1.00 & 0.9996 & 1.0023 & & & \\
\hline
\end{tabular}

RRR relative risk ratio, $C l$ confidence interval; ${ }^{*} p<0.05 ;{ }^{* *} p<0.01 ;{ }^{* * *} p<0.001$

student groups within university campuses with significantly less generalizability $[28,29]$.

The data presented on food and activity habits are self-reported and therefore subject to potential bias. Although the data on physical activity compare well with another study conducted in Malaysia [34], further research is needed, ideally using validated techniques and potentially innovative approaches, for example, taking advantage of the commonness of mobile phones to $\log$ food and physical activity habits.

The data presented are limited by their cross-sectional nature and the possible impact of cohort effects. Although it is likely that similar trends would be observed in SEACO's cohorts, further research is needed to demonstrate this and to investigate the full impact of the transition from late adolescence to early adulthood on overweight and obesity.

\section{Conclusion}

The increased overweight and obesity at older ages in the 16- to 35-year-old group illustrates that this is a significant period for changes in health-related behaviours. The changes in obesity and overweight are particularly stark because this is a predominantly rural context and in such areas it is often assumed that there are more opportunities for healthier food options and physical activity than in urban areas. Further longitudinal (qualitative and quantitative) research is however needed to confirm the observed pattern and investigate thoroughly the causal factors.

\section{Abbreviations}

BMI: Body mass index; Cl: Confidence interval; GPAQ: Global physical activity questionnaire; NCD: Non-communicable disease; ODK: Open data kit; RRR: Relative risk ratio; SD: Standard deviation; SEACO: South East Asia Community Observatory

\section{Acknowledgements}

We would like to thank the SEACO participants and the SEACO field operations team, particularly Pee Geok Lea (Dr), Thavamale D/O Ramasamy, Ramasamy A/L R. Muthusamy, Madam Kong Wey Hon, Ruhaida Bachok, Nurizwan Ahmad and Nurul Izza Azmi.

\section{Funding}

SEACO is a research technology platform of Monash University and is funded by the office of the Vice Provost Research, Monash University Australia; the Monash University Malaysia Campus, the office of the Deputy Dean Research, Faculty of Medicine, Nursing and Health Sciences, Monash University Australia and the Monash Malaysia School of Medicine and Health Sciences. The completion of this manuscript was supported by the Centre for Social Science and Global Health, University of Amsterdam. SEACO is an Associate Member of the INDEPTH Network.

\section{Availability of data and materials}

SEACO data will be made available on request. Please see http:// www.seaco.asia/research/how-to-collaborate-with-seaco/ 


\section{Authors' contributions}

CP: prepared the manuscript and revised it based on comments from COauthors. PA: conceived, designed and supervised SEACO data collection; obtained funding for SEACO; provided critical comments on the manuscript. NE: contributed to data analysis and provided critical comments on the manuscript. AH: contributed to the design of the study and provided critical comments on the manuscript. JDI: conducted preliminary qualitative that informed data collection and analysis; provided critical comments on the manuscript. IS: conducted data analysis and contributed to preparing the manuscript. DR: conceived, designed and supervised SEACO data collection; obtained funding for SEACO; provided critical comments on the manuscript. All authors: read and approved the final version of the manuscript.

\section{Competing interests}

The authors declare that they have no competing interests.

\section{Consent for publication}

Not applicable.

\section{Ethics approval and consent to participate}

Ethics approval for SEACO was obtained from the Monash University Human Research Ethics Committee (MUHREC Approval CF11/3663 - 2011001930). All SEACO participants provided written consent during data collection.

\section{Author details}

${ }^{1}$ Centre for Social Science and Global Health, University of Amsterdam, Nieuwe Achtergracht 166, 1018 WV Amsterdam, The Netherlands. ${ }^{2}$ South East Asia Community Observatory (SEACO), 6th Floor, Wisma Centrepoint, Jalan Sia Her Yam, 85000 Segamat, Johor, Malaysia. ${ }^{3}$ Global Public Health, Jeffrey Cheah School of Medicine and Health Sciences, Monash University Malaysia, Jalan Lagoon Selatan, 47500 Bandar Sunway, Selangor Darul Ehsan, Malaysia. ${ }^{4}$ EMGO Institute for Health and Care Research, VU University Medical Center, Van der Boechorststraat 7, Van der Boechorststraat 7, 1081 BT Amsterdam, The Netherlands. ${ }^{5}$ Department of Social Welfare, Faculty of Social and Political Sciences, University of Indonesia Puri Depok Mas Blok P-39, Depok 16436, West Java, Indonesia. ${ }^{6}$ Centre for Population Health Sciences, Medical School, University of Edinburgh, Teviot Place, Edinburgh EH8 9AG, Scotland.

Received: 17 February 2016 Accepted: 5 October 2016 Published online: 13 October 2016

\section{References}

1. Lim HK, Ghazali SM, Kee CC, Lim KK, Chan YY, Teh HC, Yusoff AFM, Kaur G, Zain ZM, Mohamad MHN, Salleh S. Epidemiology of smoking among Malaysian adult males: prevalence and associated factors. BMC Public Health. 2013;13:8.

2. Ng M, Fleming T, Robinson M, Thomson B, Graetz N, Margono C, Mullany EC, Biryukov S, Abbafati C, Abera SF, et al. Global, regional, and national prevalence of overweight and obesity in children and adults during 1980-2013: a systematic analysis for the Global Burden of Disease Study 2013. Lancet. 2014;384(9945):766-81.

3. Ezzati M, Hoorn SV, Lawes CM, Leach R, James WPT, Lopez AD, Rodgers A, Murray CJ. Rethinking the"diseases of affluence" paradigm: global patterns of nutritional risks in relation to economic development. PLoS Med. 2005;2:404.

4. Deurenberg-Yap M, Schmidt G, Van Staveren W, Deurenberg P. The paradox of low body mass index and high body fat percentage among Chinese, Malays and Indians in Singapore. Body Compos Diet Chin Malays Indians Singap. 2000;69.

5. Rush EC, Freitas I, Plank LD. Body size, body composition and fat distribution: comparative analysis of European, Maori, Pacific Island and Asian Indian adults. Br J Nutr. 2009;102:632-41.

6. Ntuk UE, Gill JM, Mackay DF, Sattar N, Pell JP. Ethnic-specific obesity cutoffs for diabetes risk: cross-sectional study of 490,288 UK biobank participants. Diabetes Care. 2014;37:2500-7.

7. Khambalia AZ, Seen LS. Trends in overweight and obese adults in Malaysia (1996-2009): a systematic review. Obes Rev Off J Int Assoc Study Obes. 2010;11:403-12.

8. Ministry of Health Malaysia. Malaysia Nutrition Research Priorities 2011-2015. 2009
9. Tan AKG, Yen ST, Feisul MI. Determinants of body weight status in Malaysia: an ethnic comparison. Int J Public Health. 2012;57:279-88.

10. Rampal S, Mahadeva S, Guallar E, Bulgiba A, Mohamed R, Rahmat R, Arif MT, Rampal L. Ethnic differences in the prevalence of metabolic syndrome: results from a multi-ethnic population-based survey in Malaysia. PLoS One. 2012;7, e46365.

11. Dunn RA, Tan AK, Nayga RM. Obesity inequality in Malaysia: decomposing differences by gender and ethnicity using quantile regression. Ethn Health. 2012;17:493-511.

12. Jan Mohamed HJB, Yap RWK, Loy SL, Norris SA, Biesma R, Aagaard-Hansen J. Prevalence and determinants of overweight, obesity, and type 2 diabetes mellitus in adults in Malaysia. Asia Pac J Public Health. 2014.

13. Tan AK, Dunn RA, Samad MIA, Feisul MI. Sociodemographic and healthlifestyle determinants of obesity risks in Malaysia. Asia Pac J Public Health. 2011:23:192-202.

14. Herrera BM, Keildson S, Lindgren CM. Genetics and epigenetics of obesity. Maturitas. 2011;69:41.

15. Nelson MC, Kocos R, Lytle LA, Perry CL. Understanding the perceived determinants of weight-related behaviors in late adolescence: a qualitative analysis among college youth. J Nutr Educ Behav. 2009;41:287-92.

16. Gordon-Larsen P, The NS, Adair LS. Longitudinal trends in obesity in the United States from adolescence to the third decade of life. Obesity. 2010;18:1801-4.

17. Jahan NK, Allotey P, Arunachalam D, Yasin S, Soyiri IN, Davey TM, Reidpath DD. The rural bite in population pyramids: what are the implications for responsiveness of health systems in middle income countries? BMC Public Health. 2014;14 Suppl 2:S8.

18. The World Bank: data.worldbank.org. 2015.

19. The UNESCO Institute for Statistics. Higher Education in Asia: Expanding Out, Expanding Up. Quebec: The UNESCO Institute for Statistics; 2014.

20. International Labour Organization: Youth Employment Policy Brief: Malaysia. International Labour Organization; 2013.

21. Allotey P, Reidpath DD, Devarajan N, Rajagobal K, Yasin S, Arunachalam D Debora Imelda J, Soyiri I, Davey T, Jahan N, Seaco Team T. Cohorts and community: a case study of community engagement in the establishment of a health and demographic surveillance site in Malaysia. Glob Health Action. 2014;7.

22. Baller S. Youth and the City in the Global South - Edited by Karen Tranberg Hansen. Int J Urban Reg Res. 2012;36:641-2.

23. Soo KL, Manan WWA, Suriati WW. The bahasa melayu version of the global physical activity questionnaire reliability and validity study in Malaysia. Asia Pac J Public Health. 2015;27:NP184-93.

24. Armstrong T, Bull F. Development of the World Health Organization Global Physical Activity Questionnaire (GPAQ). J Public Health. 2006;14:66-70.

25. Cleland CL, Hunter RF, Kee F, Cupples ME, Sallis JF, Tully MA. Validity of the Global Physical Activity Questionnaire (GPAQ) in assessing levels and change in moderate-vigorous physical activity and sedentary behaviour. BMC Public Health. 2014;14.

26. Tavakol M, Dennick R. Making sense of Cronbach's alpha. Int J Med Educ. 2011;2:53

27. Bland JM, Altman DG. Statistics notes: Cronbach's alpha. BMJ. 1997:314:572.

28. Khan N, Anwar M, Mohamad NA, Abdul Hameed M, Ismail NE. Eating habits and body weight profiles among undergraduate students in UiTM Puncak Alam, Selangor, Malaysia. In Humanities, Science and Engineering (CHUSER), 2011 IEEE Colloquium on. IEEE; 2011:274-280.

29. Ganasegeran K, Al-Dubai S, Qureshi AM, Al-abed AA, Am R, Aljunid SM. Social and psychological factors affecting eating habits among university students in a Malaysian medical school: a cross-sectional study. Nutr J. 2012;11:107.

30. Davey TM, Allotey P, Reidpath DD. Is obesity an ineluctable consequence of development? A case study of Malaysia. Public Health. 2013;127:1057-62.

31. Egger G, Swinburn B. An"ecological" approach to the obesity pandemic. BMJ. 1997;315:477.

32. Hawkes C. Uneven dietary development: linking the policies and processes of globalization with the nutrition transition, obesity and diet-related chronic diseases. Glob Health. 2006:2:4.

33. Baker P, Friel S. Processed foods and the nutrition transition: evidence from Asia. Obes Rev. 2014:15:564-77.

34. Ying C, Kuay LK, Huey TC, Hock LK, Hamid HAA, Omar MA, Ahmad NA, Cheong KC. Prevalence and factors associated with physical inactivity among Malaysian adults. Southeast Asian J Trop Med Public Health. 2014;45:467-80. 
35. Poh BK, Safiah MY, Tahir A, Haslinda MS, Norazlin NS, Norimah AK, Manan WW, Mirnalini K, Zalilah MS, Azmi MY. Physical activity pattern and energy expenditure of Malaysian adults: findings from the Malaysian Adult Nutrition Survey (MANS). Malays J Nutr. 2010;13-37.

36. Lachat C, Nago E, Verstraeten R, Roberfroid D, Van Camp J, Kolsteren P. Eating out of home and its association with dietary intake: a systematic review of the evidence. Obes Rev. 2012;13:329-46.

37. Larson N, Neumark-Sztainer D, Laska MN, Story M. Young adults and eating away from home: associations with dietary intake patterns and weight status differ by choice of restaurant. J American Dietetic Association 2011; 111:1696-1703.

38. Lachat C, Khan NC, Dung NQ, Do Van Anh N, Roberfroid D, Kolsteren P, et al. Eating out of home in Vietnamese adolescents: socioeconomic factors and dietary associations. Am J Clin Nutr. 2009;90:1648-55.

Submit your next manuscript to BioMed Central and we will help you at every step:

- We accept pre-submission inquiries

- Our selector tool helps you to find the most relevant journal

- We provide round the clock customer support

- Convenient online submission

- Thorough peer review

- Inclusion in PubMed and all major indexing services

- Maximum visibility for your research

Submit your manuscript at www.biomedcentral.com/submit
Biomed Central 